\title{
IN-PROCESS INTERVENTIONS
}

An Ounce of Prevention or a Pound of Cure?

Two Experiments on In-Process Interventions in Decision-Making Groups

Colin M. Fisher

University College London

Manuscript to be published in Organizational Behavior and Human Decision Processes.

Author Note

Colin M. Fisher, Department of Organisations and Innovation, School of Management, University College London.

This research was supported in part by funding from the Intelligence Technology Innovation Center, Harvard University, and Boston University. I would like to thank J. Richard Hackman, Ruth Wageman, Teresa Amabile, Anita Woolley, Nick Aramovich, GroupsGroup, HBS OBLab, Jr. BUOB, and UCL SoM Reading Group for their assistance in developing this manuscript, as well as all of the superb research assistants involved in collecting and coding these data.

Correspondence concerning this article should be addressed to Colin M. Fisher, UCL School of Management, University College London, 1 Canada Square, London E14 5AB, United Kingdom.

Email: colin.fisher@ucl.ac.uk 


\title{
IN-PROCESS INTERVENTIONS
}

An Ounce of Prevention or a Pound of Cure?

Two Experiments on In-Process Interventions in Decision-Making Groups

\begin{abstract}
This paper details two laboratory experiments about the timing of formal interventions in decision-making groups. Study 1 showed that groups receiving in-process interventions pooled more critical information and made better decisions than groups receiving pre-task interventions because in-process interventions prolonged discussions and reduced discussion of member preferences. Study 2 showed a similar pattern of results over a smaller time frame; groups receiving in-process interventions prolonged their discussions, discussed member preferences less, and pooled more critical information than those receiving pre-task interventions because they perceived those interventions as more valuable, which indirectly improved the quality of their decisions. Surprisingly, the specific timing of in-process interventions had no significant effects on information pooling or group decisions in either study. These studies collectively suggest that decision-making groups respond more strongly to interventions designed to cure process problems, rather than prevent them, which has implications for theory on formal interventions, group decision making, and group development.
\end{abstract}

Keywords: interventions, timing, group decision making, group process, information sharing 
An ounce of prevention is worth a pound of cure.

-- Benjamin Franklin

Intervening to change the behavior of in-process groups has troubled researchers and practitioners for decades (e.g., Kaplan, 1979; Wageman, Fisher, \& Hackman, 2009). Taskperforming groups quickly establish norms and work processes that shape their subsequent behavior (Bettenhausen \& Murnighan, 1985; Ericksen \& Dyer, 2004), making in-process groups resistant to change (e.g., Zellmer-Brun, Waller, \& Ancona, 2004). Decision-making groups, in particular, often struggle to alter their processes. For instance, Arthur Schlesinger tried, to no avail, to share critical information during discussions with the Kennedy cabinet to avert the Bay of Pigs fiasco (Janis, 1982), and Colin Powell tried to introduce contradictory views into the Bush cabinet's discussion of whether to invade Iraq (Woodward, 2004). Like Schlesinger and Powell, many leaders, managers, and scholars have observed decision-making groups using flawed processes, yet have been unable to alter their established trajectories.

When critical information is unevenly distributed among members, groups often reach a premature consensus, failing to use all the information that members possess (e.g., Stasser \& Titus, 1985). In such instances, some information is available to only one group member (unshared information), while other information is available to all group members (shared information). Groups tend to over-emphasize shared information and under-emphasize unshared information (e.g., Lu, Yuan, \& McLeod, 2012). Groups also focus too much on preference negotiation—advocating for and negotiating among members' preferences—which crowds out information pooling and processing (Gigone \& Hastie, 1993) and reduces the impact of new information on member preferences (Brodbeck, Kerschreiter, Mojzisch, \& Schulz-Hardt, 2007). Consequently, groups make suboptimal decisions at a disturbingly high rate when the best 


\section{IN-PROCESS INTERVENTIONS}

choice is not immediately evident to individual members (known as "hidden profiles"; e.g., Stasser \& Titus, 1985; for a review, see Lu et al., 2012). Although these problems are most pronounced when members are unfamiliar with one another (Gruenfeld, Mannix, Williams, \& Neale, 1996), groups rarely correct faulty processes on their own; dysfunctional processes can persist even when groups make many decisions over time (Gigone \& Hastie, 1993; Greitemeyer, Schulz-Hardt, Brodbeck, \& Frey, 2006).

To prevent such problems, scholars have tested many types of formal interventions, or “instructions given to groups for members to follow as they work" (Okhuysen, 2001, p. 795). Larson, Foster-Fishman, and Keys (1994), for example, randomly assigned half of their groups to receive training on group decision making before beginning their work. The training consisted of instructions to discuss task strategy, advice on how to avoid common group decision-making pitfalls, and a video of exemplary group process. Although this training prompted groups to discuss more critical information, it did not lead to higher-quality decisions; groups continued to make decisions consistent with their pre-discussion preferences. Other simple pre-task interventions, such as instructions to share information systematically (Henry, 1995), set an agenda (Mennecke, 1997), or advocate for each decision option in turn (Greitemeyer et al., 2006), have also improved information processing, but not always decision quality (e.g., Stasser, Taylor, \& Hanna, 1989; Van Swol \& Ludutsky, 2007).

Although there has been a great deal of research on what to do to help decision-making groups, there has been almost no research on when to do it. This is surprising because scholars of team coaching argue that the timing of an intervention strongly influences its effectiveness (e.g., Hackman \& Wageman, 2005; Woolley, 1998). Implicitly, most researchers have adopted Benjamin Franklin's wisdom (cf., Woolley, 1998) that pre-task interventions, focusing on 


\section{IN-PROCESS INTERVENTIONS}

preventing process problems from emerging, are more worthy of research than in-process interventions focused on curing these problems. Building on research on group decision making, group development, and formal interventions, I hypothesize and find the reverse in two laboratory experiments: in-process interventions evoke larger process and outcome changes than pre-task interventions. Because simple interventions appear to be as effective as complex ones (Okhuysen, 2001), I focus on direct instructions to share all available information, which have stimulated information pooling in previous studies (e.g., Henry, 1995; Okhuysen \& Eisenhardt, 2002) and can be easily used at any time before or during discussion.

\section{Theory and Hypotheses}

\section{In-Process vs. Pre-Task Interventions in Group Decision Processes}

In-process interventions are more likely than pre-task interventions to alter group decision processes for two reasons: (1) they interrupt premature consensus and extend discussions, and (2) they capitalize on increased group readiness for intervention once discussion is underway. Figure 1 summarizes the theoretical model and hypotheses, which are described in detail below. The bold text depicts a general model of intervention timing in groups, and italics specify the manifestations of those categories in group decision making.

[Insert Figure 1 here]

\section{In-process interventions as productive interruptions: The role of preference} negotiation and discussion length. To their detriment, many decision-making groups use preference-driven approaches to discussion (e.g., Stasser \& Birchmeier, 2003), which leads them to focus on preference negotiation and push for early consensus. At the extreme, group discussions are little more than quick votes; members strive for agreement without exploring the information underlying their competing preferences (Gigone \& Hastie, 1993; 1997). In these 


\section{IN-PROCESS INTERVENTIONS}

circumstances, in-process interventions can serve two functions. First, they should reduce

preference negotiation by interrupting premature consensus and encouraging members to adopt an information-driven approach to discussion (e.g., Stasser \& Birchmeier, 2003). When groups recognize the importance of processing information for high-quality decisions, they go beyond quick votes and discuss information more thoroughly (van Ginkel \& van Knippenberg, 2008). Second, in-process interventions can extend discussions by shifting members' attention away from their interactions and prompt them to reconsider their process and emerging consensus. These longer discussions allow groups to pool more unshared information (Parks \& Cowlin, 1995) and increase their likelihood of making high-quality decisions (Lu et al., 2012; MesmerMagnus \& DeChurch, 2009).

Group readiness for intervention. Task-performing groups are theorized to change over time in their "readiness for intervention," defined as, "the degree to which the issues to be addressed are among those naturally on team members' minds ... [and] members are not at that time preoccupied with more pressing or compelling matters” (Hackman \& Wageman, 2005, p. 275). Three factors explain why groups should be more ready for in-process interventions than pre-task ones. First, members should better understand and remember the content of interventions in process than pre-task because they have fewer competing demands on their attention. Before discussion begins, group members focus on their individual information (Tindale \& Sheffey, 2002) and worry about how their personal preferences mesh with other members' (Loyd, Wang, Phillips, \& Lount, 2013) and, in newly formed groups, how other members will perceive them (Gruenfeld et al., 1996). This leaves group members with fewer cognitive resources to devote to conducting their discussion. Once discussion begins, however, the discussion process becomes more salient and, as other members' preferences are revealed, 


\section{IN-PROCESS INTERVENTIONS}

concerns about preference fit should fade. Further, because in-process interventions interrupt discussion, they should easily attract members' attention. Thus, members are more likely to understand and remember in-process interventions than pre-task interventions.

Second, groups should view in-process interventions as more valuable than pre-task interventions. Members are most likely to see interventions as valuable when they align with their current attentional focus and concerns (Hackman \& Wageman, 2005). Construal level theory (e.g., Trope \& Liberman, 2010) helps explain why groups should perceive more value in in-process than pre-task interventions. Construal level theory predicts that more temporally distant targets will be viewed more abstractly, while more temporally proximate objects will be viewed more concretely (Eyal, Liberman, Trope, \& Walther, 2004). Abstract construals (highlevel construals) are linked to questions of "why," while concrete construals (low-level construals) are linked to questions of "how" (Trope \& Liberman, 2010). Formal interventions instructing groups about their processes are fundamentally questions of "how" and should be better aligned with more concrete, low-level construals. Thus, before work on a given decision has begun, members should view discussion more abstractly because it is more temporally distant. However, once discussion has begun, it is more temporally proximate, and the group and task become more concrete, increasing members' focus on how to conduct their discussion. Further, groups tend to vary over time in their focus on task and relational issues (i.e., Bales \& Strodbeck, 1951; Tuckman, 1965). Like other kinds of groups, decision-making groups tend to focus on relational issues, such as building trust and affinity, earlier in discussion (Fisher, 1970), while discussing and resolving points of contention later (Jehn \& Mannix, 2001; Lim \& Murnighan, 1994). Groups should see in-process interventions as aligned with their lower-level construals and focus on the task, and thus see more value in them than in pre-task interventions. 


\section{IN-PROCESS INTERVENTIONS}

Third, group readiness may be associated with the degree to which interventions increase members' experience of process accountability - individuals' perceptions that they need to explain or account for the way in which they work (Lerner \& Tetlock, 1999). Process accountability enhances information processing and decision quality in groups because it increases members' motivation to understand the issue deeply (De Dreu, Koole, \& Steinel, 2000; Scholten, van Knippenberg, Nijstad, \& De Dreu, 2007). Formal interventions give groups specific goals for their process that help structure and pace their work (Okhuysen \& Eisenhardt, 2002). This structuring and pacing should be easier with in-process rather than pre-task interventions. For instance, if an in-process intervention instructs groups to focus on sharing all available information, members can evaluate the extent to which their ongoing discussion accomplishes this aim. With pre-task interventions, groups have no ongoing process to observe, making it more difficult for them to engage in such assessments. This focus and assessment of process should manifest as process accountability.

The logic above suggests that in-process interventions should elicit larger changes in group process than pre-task interventions will because they extend discussions, preempt early consensus, are better understood, are seen as more valuable, and increase process accountability. In the context of group decision making, those process changes include longer discussions and increased pooling of unshared information. To pool more unshared information, groups must also reduce preference negotiation. As summarized in Figure 1, these process changes should lead groups receiving in-process interventions to make better decisions than those receiving pretask interventions:

Hypothesis 1a: In-process interventions will promote better decisions than pre-task interventions. 


\section{IN-PROCESS INTERVENTIONS}

Hypothesis 1b: The effects of in-process interventions on decision quality will be mediated by unshared information pooling.

Hypothesis 1c: The effects of in-process interventions on unshared information pooling will be mediated by longer group discussions and decreased preference negotiation.

Hypothesis 2a: Members will better understand in-process interventions than pre-task interventions.

Hypothesis 2b: Members will perceive in-process interventions as more valuable than pre-task interventions.

Hypothesis 2c: Members will experience more process accountability when given inprocess interventions than when given pre-task interventions.

Hypothesis 2d: These differences in psychological readiness will mediate the impact of in-process interventions on group decision processes and outcomes.

\section{In-Process Intervention Timing: Midpoints and Beginnings}

The arguments above suggest that curing decision-making groups of their process problems will be more effective than trying to prevent these problems from occurring in the first place. The effectiveness of in-process interventions, however, may vary over the course of discussion. Research suggests two moments of heightened readiness for in-process interventions: the temporal midpoint (Hypothesis 3) and the very beginning of discussion (Hypothesis 4). Between these times, interventions may come too early to capitalize on heightened readiness at the temporal midpoint but too late to capitalize on heightened readiness at the outset of discussion. 


\section{IN-PROCESS INTERVENTIONS}

Midpoints as times of heightened readiness. Group development and team coaching scholars have theorized that group readiness for task-focused interventions is highest at the temporal midpoint (Woolley, 1998). For instance, Hackman and Wageman (2005) argued, "beginnings are not a good time for strategy discussions, but . . midpoints are" (p. 276). Punctuated equilibrium theories of group development emphasize the role of clock time in structuring and pacing group process. When half of their allotted time has elapsed, groups pay more attention to clock time (Gersick, 1989; Chang, Bordia, \& Duck, 2001). When groups shift their attention from working on the task at hand to clock time, they are also more likely to propose and introduce changes to their work processes (Okhuysen \& Waller, 2002). In-process interventions at the clock-determined midpoint of the task should align with this tendency (Woolley, 1998). Further, groups should benefit more from discussing their performance strategies later rather than earlier because they have more collective experience to reflect on and a better sense of the interface between members' knowledge and skills and the task at hand (Chang et al., 2003; Kozlowski \& Bell, 2008).

Hypothesis 3a: In-process interventions received at the temporal midpoint will promote better decisions than in-process interventions received at other times. Hypothesis 3b: The effects of in-process intervention timing on decision quality will be mediated by unshared information pooling.

Hypothesis 3c: The effect of in-process intervention timing on unshared information pooling will be mediated by longer group discussions and decreased preference negotiation. 


\section{IN-PROCESS INTERVENTIONS}

Beginnings as times of heightened readiness. Many scholars of group development suggest that the very beginning of a group's interaction is also a pivotal moment when process is especially malleable (Wageman et al., 2009). Members' interaction patterns, roles, and norms emerge quickly (Bettenhausen \& Murnighan, 1985; 1991). Those patterns, once established, tend to persist for at least the first half of the task (Gersick, 1988). Intervening immediately after discussion begins should both target processes when they are especially malleable and harness the benefits of in-process interventions for longer periods of time. In addition, research on decision-making groups suggests several disadvantages of waiting too long to intervene. Early in their discussions, decision-making groups tend to exchange and justify their pre-discussion opinions (Brodbeck et al., 2007; Gigone \& Hastie, 1993). When members declare and justify their preferences to the group, this increases their commitment to these initial preferences (Greitemeyer \& Schulz-Hardt, 2003) because members feel socially obligated to maintain consistency. Further, discussing one's preference increases its salience, strengthening confirmation and evaluation biases (Brodbeck et al., 2007), such that preference-consistent information is better remembered and integrated into individual decisions (Van Swol, Savadori, \& Sniezek, 2003).

Thus, the very beginning of discussion may be a moment when interventions have a greater chance to alter group decision-making processes because they occur when group processes are more malleable, preserve more time to work on the task, and allow group discussion to shape member preferences before they are entrenched. This should create a window of opportunity during which decision-making groups experience heightened readiness for intervention: 


\section{IN-PROCESS INTERVENTIONS}

Hypothesis 4a: In-process interventions received at the very beginning of discussion will promote better decisions than in-process interventions at other times.

Hypothesis 4b: The effects of in-process intervention timing on decision quality will be mediated by unshared information pooling.

Hypothesis 4c: The effect of in-process intervention timing on unshared information pooling will be mediated by longer group discussions and decreased preference negotiation.

\section{Overview}

I present two laboratory experiments using hidden profile decision-making tasks that test the hypotheses above. Study 1 tests hypotheses 1 and 3, comparing the effects of pre-task interventions and in-process interventions given before and at the temporal midpoint on discussion time, preference negotiation, information pooling, and decision quality. Study 2 presents a more conservative test of Hypothesis 1, with smaller temporal differences between pre-task and in-process interventions, examines the indicators of group readiness for intervention as specified in Hypothesis 2, and tests Hypothesis 4, comparing in-process interventions given at the outset of discussion and in-process interventions given a few minutes into discussion.

\section{Study 1}

\section{Method}


Participants. Sixty-four three-person groups ${ }^{1}$ comprised of 192 individuals $\left(M_{\text {age }}=\right.$ $28.5, S D=11.7,49 \%$ were female) were recruited via classified advertising in a major city in the Northeastern United States. Individuals were paid \$20 for their participation.

Task and materials. Participants were asked to imagine they were part of a three-person group of investors opening a new gourmet restaurant. To examine whether the effects of intervention persisted in a subsequent decision, each group performed two hidden-profile decision-making tasks (Stasser \& Titus, 1985), choosing (a) one of three finalists for the position of head chef and (b) one of three locations to rent.

Consistent with prior hidden profile research, information favoring the two incorrect choices was held jointly by all three group members (i.e., shared information), while information favoring the correct choice was distributed so that a subset was held uniquely by each group member (i.e., unshared information) (e.g., Wittenbaum, Hollingshead, \& Botero, 2004). For each decision, the group held a total of 18 pieces of shared information and 27 pieces of unshared information (see Appendix A for the full information distribution).

Procedure. When all three group members arrived, participants were given information packets for the first task. An experimenter who was blind to hypotheses explained the task instructions, asking participants not to show their packets to one another. Participants were instructed to read their individual information and indicate which option they felt was best, which option they felt was worst, and their confidence in those rankings and, after doing so, to begin discussion of which option the group should choose (e.g., Greitemeyer et al., 2006; Stasser $\&$ Titus, 1985). Groups were given a maximum of 30 minutes to make each decision. All

\footnotetext{
${ }^{1}$ Eight teams were excluded from the analyses because either they did not follow task instructions, they finished discussion before the intervention, or the experimenter intervened more than 45 seconds differently from the targeted timing.
} 
sessions were video-recorded. After groups completed their first decision, the experimenter distributed information packets for the second decision. The sequence of the two decisions was counterbalanced within condition.

Manipulation. $^{2}$ In all conditions, the experimenter verbally gave the following intervention to the group as a whole during the first task: "I'd like to give you some advice about how to conduct your discussion. Try to share as much information as possible before coming to a decision - having all the information available will help your team to make the best choice." Groups were randomly assigned to receive this intervention at one of three times: (1) pre-task, in which groups were given interventions before participants read their information packets (pretask interventions; $n=27$ ); (2) five minutes after group discussion began (early in-process interventions; $n=19)$; and (3) at the temporal midpoint, 15 minutes after groups began discussion (midpoint in-process interventions; $n=18$ ). For pre-task interventions, the experimenter gave the intervention after explaining the task and procedure but before participants began reading their information packets. For in-process interventions, the experimenter left the room as members read their information packets and waited in an adjacent control room, watching a live video feed of the group. He then reentered the room at the appointed time and gave the intervention.

Measures. Two research assistants, blind to hypotheses, independently coded videos for discussion length, preference negotiation, and information pooling. To measure discussion length, coders recorded the number of minutes and seconds from the moment a group member

\footnotetext{
2 Study 1 was part of a larger study designed to test hypotheses about the interaction between intervention style (i.e., directive vs. participative) and intervention timing. One of these hypotheses concerned the persistence of intervention effects, so the study design incorporated two decision tasks. The style manipulation, however, was ineffective. I thus omit the groups receiving participative interventions from the methods and results. However, including them does not change any of the patterns of results about timing presented here.
} 


\section{IN-PROCESS INTERVENTIONS}

began a speaking turn that elicited a response from another member until the group finished filling out its final decision form. To measure preference negotiation, the coders rated the group on four questions using five-point agree-disagree scales for every five-minute period of discussion. Questions included: "How much did members evaluate or interpret information as it was being shared for the first time?" and "How much of the group's discussion during this time period was based on arguing for or against a specific group member's preferences?" The items comprising the scale showed sufficiently high internal reliability (Cronbach's alpha $=.88$ ) to average them into a single measure. For the analyses below, preference negotiation refers to standardized $Z$ scores of this scale, with lower levels indicating a more desirable group process.

Unshared and shared information pooling variables were calculated as the sum of the unique pieces of information the group pooled; thus, a piece of information was counted when it was first introduced but not when it was repeated. Because patterns of shared and unshared information pooling were nearly identical and were predicted by the same factors, but only unshared information pooling is linked theoretically to decision quality (Brodbeck et al., 2007), only unshared information pooling is reported, although including shared information pooling in the analyses does not change the patterns of results.

The two coders watched 39 and 40 of the 64 videos, respectively, and coded an average of 6,106 pieces of information and 285 five-minute periods. Inter-rater reliability was calculated from 15 videos, 99 five-minute periods, and 2,465 pieces of information rated by both. Interrater reliability was assessed using Krippendorff's alpha (e.g., Hayes \& Krippendorff, 2007), and reliability was good for all measures $\left(K \alpha_{\text {Length }}=.98 ; K \alpha_{\text {PreferenceNegotiation }}=.88 ; K \alpha_{\text {InfoPooling }}=.95\right)$. The author resolved disagreements between the two coders for information pooling. Discussion length and preference negotiation were calculated as the mean of the coders' estimates. 


\section{IN-PROCESS INTERVENTIONS}

Decision quality was coded as either correct (1) or incorrect (0). Pre-discussion preferences were measured as the number of members who preferred the correct answer before discussion. ${ }^{3}$ A dummy code for the first task showed differences between the first and second $\operatorname{task}($ Task $1=1$, Task $2=0)$.

Analytic approaches. Because the data structure was pooled repeated measures $(n=$ 128; 64 groups $\times 2$ decision tasks), I used generalized estimating equations (GEEs) to test hypotheses. GEEs provide maximum likelihood estimates that account for the correlation between multiple measurements from the same group (i.e., the within-group correlation between the first and second tasks) and allow for time-varying covariates (i.e., different initial preferences in the first and second tasks) (Ballinger, 2004). These analyses were conducting using the GENLIN command in SPSS 22, specifying an exchangeable correlation matrix (Ballinger, 2004), a maximum of 5,000 iterations, and robust standard errors (Huber, 1977); responses were clustered by group. When discussion length and preference negotiation were dependent variables, a normal link function was specified. When unshared information pooling was the dependent variable, a negative binomial link function was specified, which is appropriate for count variables that cannot be less than zero (Hilbe, 2011). When decision quality was the dependent variable, a binomial link function was specified. The estimated marginal means based on these analyses summarize all observations within condition (i.e., aggregating both Task 1 and Task 2).

Following Hayes and Preacher's (2014) recommendations for conducting mediational analyses with multi-categorical independent variables, I created two contrast codes to represent

\footnotetext{
${ }^{3}$ Computing initial preferences as categorical variables (e.g., unanimous incorrect, majority incorrect/minority correct, etc.) does not change the patterns of results; however, the model fit statistics (i.e., QIC, QICC) indicated better model fits using the continuous rather than categorical measure in the majority of cases.
} 


\section{IN-PROCESS INTERVENTIONS}

Hypotheses 1 and 3 respectively. The first contrast (In-process Contrast; Hypothesis 1) tests for pairwise differences between pre-task interventions, coded as -.67, to in-process interventions, coded as .33. The second contrast (Midpoint Contrast; Hypothesis 3), tests for pairwise differences between earlier (coded as -.5) and midpoint (coded as .5) in-process interventions; pre-task interventions were coded as 0 for this contrast.

Because it is difficult to test mediation with pooled, repeated-measures data with nonnormal dependent variables, I tested for mediation by triangulating three approaches: (a) causal steps (Baron \& Kenny, 1986), (b) bootstrapping to estimate confidence intervals for indirect effects (Hayes \& Preacher, 2014; Preacher \& Hayes, 2008), and (c) Sobel tests (Sobel, 1982) based on GEEs. I obtained the bootstrapped confidence intervals for indirect effects using Hayes (2013) PROCESS (v2.13) module for SPSS 22 (Models 4 and 6). Because these approaches do not account for nested data (Hayes, 2013), I report the more conservative 99\% confidence intervals rather than 95\% confidence intervals. Sobel's $Z$ was computed with Preacher and Leonardelli's (2015) formula, using the regression weights and standard errors from GEEs, which accounts for the nested data structure, but may be overly conservative and make restrictive distributional assumptions (Preacher \& Hayes, 2008).

To analyze precisely when changes occurred in response to intervention (i.e., discussion length, information pooling, preference negotiation), I examined each five-minute period of group discussion. Using GEEs, I modelled the effects of the 12 five-minute periods across the two tasks ("Period") and the interactions between dummy variables for each period and experimental condition. For these analyses, an auto-regressive lag-1 correlation matrix was used, specifying the assumption that the correlations between adjacent time periods would be stronger than between more distal ones. The Period*Condition interaction tests whether differences 


\section{IN-PROCESS INTERVENTIONS}

between conditions occur in different periods, controlling for the main effects of period and condition. The test statistics from these analyses are included in Appendix B. Post-hoc leastsquare differences pairwise comparisons were used to test the differences between periods and conditions. The periods immediately after each intervention are of special interest. The immediate effects of pre-task interventions should manifest during Period 1 , the effects of early in-process interventions should manifest during Period 2, and the effects of midpoint in-process interventions should manifest during Period 4.

\section{Results}

Preparatory analyses. First, I tested that initial preferences were not confounded with experimental condition and found that the distribution of initial preferences across conditions did not significantly differ from a random one, Pearson's $\chi^{2}(4)=1.42, p=.84$. Second, GEEs testing whether the sequence of tasks (e.g., chef then location vs. location then chef) affected group processes and outcomes (i.e., discussion time, preference negotiation, information pooling, decision quality) revealed no significant associations, all $p \mathrm{~s}>.57$.

Hypotheses tests. Hypothesis la posited that in-process interventions would lead groups to make better decisions than pre-task interventions. As shown in Table 1, Model 5, this hypothesis was supported, $\chi^{2}(1)=8.56, p=.003$. Estimated marginal means are shown in Table 2.

[Insert Table 1 and Table 2 here]

Hypothesis $1 \mathrm{~b}$ stated unshared information pooling would mediate this effect. This hypothesis was also supported. As shown in Table 1, Model 3, in-process intervention groups pooled more unshared information than pre-task intervention groups, $\chi^{2}(1)=26.13, p<.001$. As shown in Table 3, Line 1, unshared information mediated the effect of interventions on decision 


\section{IN-PROCESS INTERVENTIONS}

quality using all three approaches. Further, changes in information pooling corresponded to the timing of in-process interventions but not pre-task ones. In Period 1, although pre-task groups pooled slightly more unique information $(M=8.66, S E=.61)$ than in-process groups $(M=7.49$, $S E=.56$ ), this difference was not significant, $p=.14$. As expected, in Period 2, early in-process interventions led to more unshared information pooling $(M=5.96, S E=.70)$ than did pre-task $(M=3.78, S E=.68)$ or midpoint in-process interventions $(M=3.77, S E=.48), p<.05$. In Period 4, midpoint in-process interventions also led to more unshared information pooling $(M=$ $3.41, S E=.47)$ than did pre-task $(M=.29, S E=.19)$ and early in-process interventions $(M=$ $1.64, S E=.48), p<.01$. Figure 2 shows these changes in group process over time.

[Insert Table 3 and Figure 2 here]

Hypothesis 1c posited that the effect of in-process interventions on unshared information pooling would be mediated by discussion length and preference negotiation. As predicted, groups receiving in-process interventions showed significantly lower levels of preference negotiation than did groups receiving pre-task interventions, $\chi^{2}(1)=12.16, p<.001$ (see Table 1 , Model 2; Table 2). As shown in Figure 2, the level of preference negotiation significantly declined in the five minutes following in-process interventions. Period 1 did not show significant differences based on experimental condition, $p>.49$, suggesting little effect of pre-task interventions. As expected, early in-process interventions led groups to reduce preference negotiation from Period $1(M=.18, S E=.20)$ to Period $2(M=-.36, S E=.22)$, a marginally significant change, $p=.06$; the other two conditions did not change significantly, $p>.55$. Similarly, midpoint in-process groups declined when the intervention was given from Period 3 $(M=.42, S E=.19)$ to Period $4(M=-.49, S E=.23 ; p<.001)$, while other groups increased non-significantly, $p>.14$. 


\section{IN-PROCESS INTERVENTIONS}

Similar results were obtained for discussion length: Groups receiving in-process interventions held longer discussions than groups receiving pre-task interventions, $\chi^{2}(1)=25.43$, $p<.001$ (see Table 1, Model 1). Patterns of continuing discussion also corresponded to intervention timing. As illustrated in Figure 2, the time period during which groups finished deliberation was strongly related to condition: By the third period, only $44 \%$ of groups receiving pre-task interventions were still deliberating. In contrast, $97 \%$ of groups receiving in-process interventions deliberated during the third period, a significant difference, $p<.001$.

Further supporting Hypothesis 1c, the effects of in-process interventions had indirect effects on information pooling via discussion length (Table 3, line 2) and preference negotiation (Table 3, line 3). The two-step indirect effects of in-process interventions on decision quality were also supported (Table 3, lines 5, 7). Hypothesis 1c thus received strong support.

Hypotheses 3 posited differences between midpoint and early in-process interventions. This hypothesis was not supported. As shown in Table 2, the contrast between midpoint and early in-process interventions did not significantly predict preference negotiation (Model 2), information pooling (Model 3), or decision quality (Model 5). While midpoint interventions led to marginally longer discussions than earlier interventions, $\chi^{2}(1)=2.81, p=.09$, this did not increase information pooling or improve decision quality. Because there were no main effects of the timing of in-process interventions on information pooling or decision quality, further tests of mediation were unnecessary.

\section{Discussion}

Most importantly, Study 1 provided support for the hypothesis that decision-making groups benefit more from in-process than pre-task interventions. These results further suggest that in-process interventions are effective because they lengthen discussions and reduce 


\section{IN-PROCESS INTERVENTIONS}

preference negotiation, which provides more time and attention for pooling distributed information. This study, however, did not find support for increased intervention readiness at the temporal midpoint of the task that team-coaching scholars have predicted (Hackman \& Wageman, 2005; Wageman et al., 2009; Woolley, 1998). Instead, earlier in-process interventions were just as effective as midpoint ones at improving group processes and outcomes.

There are several potential explanations for why midpoint interventions failed to outperform earlier interventions. First, decision-making groups may not experience transitions at the temporal midpoint, instead clustering mentions of time and activity shifts near the deadline (Lim \& Murnighan, 1994). Second, most groups in this study did not use the entire 30 minutes to complete each task; group discussions lasted an average of only 17.14 minutes $(S E=.53)$. Because groups likely experienced little time pressure, they may have paid less attention to clock time, undermining the clock-defined midpoint as a point of readiness. Thus, midpoint interventions may have been experienced as occurring quite late in discussion when groups were nearing agreement, making it somewhat surprising that they were effective at all.

These findings raise a conceptual and practical issue in studying clock-based transitions in group decision making. Although it has been said that "work expands so as to fill the time available for its completion," (Parkinson, 1955), group decisions often are hastily made (Gigone $\&$ Hastie, 1993), regardless of the time allotted. This may reduce the importance of clock time as a source of pacing and as a trigger for the attention switches necessary for process transitions (Okhuysen \& Waller, 2002). Previous studies of midpoint transitions have measured the midpoint as half the clock time available rather than half the time used or half of the task completed (Okhuysen \& Waller, 2002; Woolley, 1998; Gersick, 1988; 1989; Lim \& Murnighan, 


\section{IN-PROCESS INTERVENTIONS}

1994; Chang et al., 2001). However, these studies do not report whether groups actually used all the time allotted. Future research should examine issues of timing in situations in which groups have abundant time, which may decrease experienced time pressure and attention to clock time that cause midpoint transitions, and consider other potential triggers for transitions, such as task progress or internal sense of time.

This study also had several limitations. First, pre-task interventions were surprisingly ineffective in this study, perhaps because they were so much less salient than in-process interventions. The pre-task intervention was given immediately after other instructions about the task and preceded individuals reading their information packets. Although it is part of the hypothesized phenomenon that pre-task interventions are less salient than in-process ones, the specific timing of the pre-task intervention may have exaggerated this effect. Further, this study did not directly measure indicators of group readiness for intervention, instead relying on process changes as a proxy. These limitations are addressed in Study 2 below.

\section{Study 2}

The goals of Study 2 were (a) to replicate the finding that groups respond more strongly to intervention in-process than pre-task, using a more conservative test (Hypothesis 1); (b) to investigate the role of three indicators of group readiness for intervention: intervention understanding, perceived value, and process accountability (Hypothesis 2); and (c) to examine the effects of changes in in-process intervention readiness immediately after discussion begins (Hypothesis 4).

\section{Method}




\section{IN-PROCESS INTERVENTIONS}

Participants. Sixty groups comprised of 180 English-speaking adults were recruited in the same manner described in Study $1\left(M_{\text {age }}=28.7, S D=12.1 ; 56 \%\right.$ female $)$. Individuals were paid $\$ 15$ for participation.

Procedure. The procedure was identical to Study 1, with several exceptions. First, based on the results of Study 1, participants were given only 20 minutes to make each decision. Second, the pre-task intervention was given after participants had read their information packets (instead of before they had read them, as in Study 1).

Manipulation. Groups were randomly assigned to one of three intervention timings during the first task, so that each condition contained 20 groups: (a) pre-task interventions, given after all members had finished indicating their individual preferences but before discussion began; (b) immediate in-process interventions, given after the first speaking turn to elicit a response from another group member (generally less than one minute after the pre-task intervention); or (c) early in-process interventions, five minutes after group discussion began (replicating the early in-process condition in Study 1). As in Study 1, the experimenter verbally gave groups the following intervention before or during the first task: "I'd like to give you one piece of advice about the process you use. We've found it helps groups to collect all the information before discussing its importance. This should be helpful in your discussion."

Measures. Indicators of group readiness for intervention were measured using a survey administered at the end of the study. First, intervention understanding was measured with six true/false questions about the content of the intervention (e.g., "The experimenter suggested that we should share all the information we had before we discussed which option to choose"); the sum of the correct answers was used as a measure of intervention understanding. Second, perceptions of the value of the intervention were measured using a 5-item scale (e.g., "The 


\section{IN-PROCESS INTERVENTIONS}

advice we received from the experimenter helped our group improve its process.”). Internal consistency for this scale was good $(\alpha=.84)$, and inter-member agreement was adequate for aggregation to the group level $(I C C(2)=.70)$. Third, members' process accountability was measured using three items adapted from Hochwarter, Ferris, Perrewé, Hall, and Frink's (2007) measure of felt accountability that were applicable to ad-hoc groups and process (e.g., "We were held very accountable for the process by which we reached a decision"). Internal consistency for this scale was good $(\alpha=.84)$, and inter-member agreement was adequate for aggregation to the group level $(\operatorname{ICC}(2)=.74)$.

Information pooling, preference negotiation, discussion time, and decision quality were measured as they were in Study 1. Three independent coders blind to hypotheses coded the videos. All three coders coded 40 of the 60 videos, such that two coders rated each video. Each coder coded an average of 1,974 pieces of information and 231 five-minute periods; reliability was acceptable for all measures $\left(K \alpha_{\text {Length }}=.97 ; K \alpha_{\text {PreferenceNegotiation }}=.78 ; K \alpha_{\text {InfoPooling }}=.94\right)$.

The same pattern of contrast coding used in Study 1 (Hayes \& Preacher, 2014) was used to test Hypotheses 1, 2, and 4. The "In-process Contrast" was coded as it was in Study 1. The "Immediate Contrast" used to test Hypothesis 4 examines pairwise differences between immediate (coded as -.5) and earlier (coded as .5) in-process interventions, with pre-task interventions coded as 0 .

As in Study 1, GEEs testing the interaction between condition and the eight five-minute periods were used to examine precisely when changes occurred in response to intervention. The model summaries are shown in Appendix B. In Period 1, differences between pre-task and early in-process should be manifest; in Period 2, early in-process interventions should evoke stronger 


\section{IN-PROCESS INTERVENTIONS}

responses. Because immediate interventions were given during Period 1, their effects should be evident in both Periods 1 and 2 .

\section{Results}

Preliminary analyses. Initial preferences were not associated with experimental condition, $\chi^{2}(4)=1.67, p=.80$. Task sequence did not significantly affect any criterion variables at the $p<.05$ level.

Hypothesis tests. Hypothesis 1a posited that in-process interventions would lead groups to make better decisions than pre-task ones. As shown in Table 4, Model 5, groups receiving inprocess interventions did not make significantly better decisions than did groups receiving pretask interventions, $\chi^{2}(1)=.87, p=.34$. While these results do not directly support Hypothesis $1 \mathrm{a}$, there were significant indirect relationships between in-process interventions and decision quality, discussed below. Means for the dependent variables are displayed in Table 5.

[Insert Table 4 and Table 5]

Hypothesis $1 \mathrm{~b}$ posited that in-process interventions would lead groups to pool more information than pre-task interventions would, leading to improved decisions. Supporting this notion, groups receiving in-process interventions pooled more information than those receiving pre-task interventions, $\chi^{2}(1)=4.70, p=.03$ (see Table 4, Model 3; Table 5). As noted in Table 6, line 1 , in-process interventions indirectly affected decision quality via information pooling. Thus, Hypothesis $1 \mathrm{~b}$ received qualified support. As in Study 1, changes in information pooling corresponded with intervention timing. In Period 1, pre-task interventions spurred groups to pool 6.39 pieces of unshared information $(S E=.64)$, while immediate in-process groups pooled 5.65 $(S E=.30, p=.14)$ and early in-process groups pooled $5.37(S E=.45, p=.08)$. In Period 2, pretask groups pooled less information $(M=3.91, S E=.51)$ than either early in-process $(M=5.67$, 


\section{IN-PROCESS INTERVENTIONS}

$S E=.63, p=.03)$ and, marginally, immediate in-process $(M=5.59, S E=.84 ; p=.09)$ groups.

Figure 3 shows the patterns of group processes over time.

[Insert Figure 3 and Table 6 here]

Hypothesis 1c posited that the effect of interventions on information sharing and decision quality would be mediated by the extent to which interventions lengthened discussions and reduced preference negotiation. This hypothesis was supported. As shown in Table 4, Model 1, groups receiving in-process interventions held longer discussions than those receiving pre-task interventions, $\chi^{2}(1)=6.25, p=.01$. Discussion length fully mediated the effect of in-process interventions on information sharing using the causal steps approach and had a significant indirect effect using the other two approaches (Table 6, line 2). As noted on Table 6, line 3, the causal chain from discussion length to information pooling to decision quality was also supported by all three approaches, replicating the findings of Study 1 . The indirect effect of inprocess interventions on decision-quality via discussion length and unshared information pooling was also significant (Table 6, line 4). As shown in Figure 3, differences emerged in Period 3, when $50 \%$ of pre-task groups had ongoing discussions, significantly less than the $85 \%$ of groups receiving early in-process interventions, $p=.01$, though not significantly different than the $70 \%$ of groups receiving immediate in-process interventions.

Preference negotiation also mediated the effects of interventions on information pooling (Table 6, line 5), and the indirect effect of in-process interventions via preference negotiation and information pooling was also significant (Table 6, line 7). As predicted, in-process interventions led to lower levels of preference negotiation, $p=.01$ (see Table 4, Model 2; Table 5). As in Study 1, preference negotiation changed in response to in-process, but not pre-task, interventions. In Period 1, there were no significant differences among conditions, $p>.22$. As 


\section{IN-PROCESS INTERVENTIONS}

expected, early in-process interventions led to a decline in preference negotiation from Period 1 $(M=-.32, S E=.16)$ to Period $2(M=-.65, S E=.22), p=.04$. In Period 2, the level of preference negotiation was lower for early in-process groups than for pre-task groups $(M=.22$, $S E=.21 ; p=.004)$, though not between immediate and early in-process interventions $(M=-.13$, $S E=.24 ; p=.11)$

Hypothesis 2a-c posited three indicators of group readiness for intervention. Independent samples t-tests at the group level $(n=60)$ showed that groups receiving in-process interventions understood that intervention better than groups receiving pre-task interventions $\left(M_{\text {in-process }}=4.44\right.$, $S E=.12 ; M_{\text {pre-task }}=4.02, S E=.14, t(58)=2.14, p=.04 ;$ Hypothesis $\left.2 \mathrm{a}\right)$ and perceived the intervention as more valuable $\left(M_{\text {in-process }}=4.80, S E=.14 ; M_{\text {pre-task }}=4.15, S E=.10, t(58)=2.12\right.$, $p=.04$; Hypothesis $2 \mathrm{~b})$. There were no such differences in process accountability $\left(M_{\text {in-process }}=\right.$ $5.44, S E=.07 ; M_{\text {pre-task }}=5.57, S E=.08, t(58)=-1.03, p=.31 ;$ Hypothesis $\left.2 \mathrm{c}\right)$. As shown in Table 7, perceived value also significantly predicted discussion length and information pooling, but not preference negotiation or decision quality, while intervention understanding and process accountability did not significantly predict any of these variables.

[Insert Table 7]

Hypothesis $2 \mathrm{~d}$ predicts that group readiness will mediate intervention effects on group processes and outcomes. As shown in Table 7, line 8, the effect of in-process interventions on discussion length was mediated by perceived value, according to all three approaches. As shown in Table 7, line 10, there was a significant indirect effect of in-process interventions on decision quality via perceived value, discussion length, and unshared information pooling. Neither intervention understanding nor process accountability showed similar significant effects. Thus, 


\section{IN-PROCESS INTERVENTIONS}

perceptions of intervention value were the strongest indicator of group readiness for intervention in this study.

Hypothesis 3a-d predicted that interventions given immediately after discussion began would be more effective than interventions given later, in process. These hypotheses were not supported. As shown in Table 3, using the immediate contrast code, immediate in-process interventions did not differ from early ones in discussion time (Model $\left.1, \chi^{2}(1)=.34, p=.56\right)$, preference negotiation (Model 2, $\left.\chi^{2}(1)=.10, p=.75\right)$, unshared information pooling (Model 4, $\left.\chi^{2}(1)=.77, p=.38\right)$, or decision quality (Model 5, $\left.\chi^{2}(1)=.76, p=.38\right)$.

\section{Discussion}

The results of Study 2 substantiated the conclusions of Study 1, replicating the differences between pre-task and in-process interventions in stimulating unshared information pooling, mediated by lengthening discussions and reducing preference negotiation. It also provided stronger evidence that groups change in readiness for intervention at the onset of discussion: the pre-task intervention was given right before discussion began, while the inprocess interventions were both given within the first five minutes, suggesting that these effects emerge over very small time horizons. Further, both studies failed to find times of heightened readiness for in-process interventions during discussion (i.e., immediately after discussion began or near temporal midpoint), which implies that readiness changes most strongly at the onset of discussion but varies less during discussion.

Study 2 also provided preliminary evidence about indicators of group readiness for intervention: Groups were more responsive to in-process interventions because they perceived them as more valuable rather than because they better understood them or experienced increased process accountability. This supports the theoretical role of group readiness for intervention but 


\section{IN-PROCESS INTERVENTIONS}

suggests that perceived value may be a more promising topic for future research on group readiness for intervention than understanding and accountability are.

Although the direct effect of in-process interventions on decision quality was not significant in Study 2, the indirect effects of interventions on decision quality via discussion length and information pooling were. Because pooling unshared information is a well-established way to improve decision quality (e.g., Mesmer-Magnus \& DeChurch, 2009), I conclude that these two studies are theoretically consistent. That said, there are several reasons why Study 2 may not have shown a direct effect on decision quality. First, the temporal distance between pretask and in-process interventions was much smaller in Study 2 than in Study 1, making their effects on processes and outcomes correspondingly smaller. Second, groups in Study 2 had shorter deadlines than in Study 1, leading to shorter discussions $\left(M_{S t u d y 1}=17.14, S E=.53\right.$; $\left.M_{S t u d y 2}=13.75, S E=.51\right)$ and less information pooling $\left(M_{S t u d y 1}=18.15, S E=.36 ; M_{S t u d y 2}=\right.$ 14.02, $S E=.44)$. These tighter deadlines likely increase people's experience of time pressure, which heightens their desire for cognitive closure and thus increases the urgency with which they work and their desire to "freeze" any potential sources of uncertainty (Kruglanski \& Webster, 1996). This heightened need for closure also makes people more confident in their initial judgments and more reliant on early cues (Kruglanski \& Webster, 1996; Kelly \& Karau, 1999), and strengthens conformity pressures in groups (Kruglanski, Webster, \& Klem, 1993). Further, fewer groups may have pooled enough unshared information to reveal the correct answer (Winquist \& Larson, 1998). Thus, deadlines may act as a moderator of the effects presented here, with increased time pressure weakening the advantages of in-process interventions over pre-task ones.

\section{General Discussion}




\section{IN-PROCESS INTERVENTIONS}

In past research, group decision-making scholars behaved as if "an ounce of prevention is worth a pound of cure"; interventions were given pre-task to prevent dysfunctional processes from taking root. In contrast, this paper develops and finds support for the hypothesis that decision-making groups are better cured than inoculated. In two studies, decision-making groups showed more readiness for intervention after the discussion began, leading in-process interventions to evoke larger process and outcome improvements than pre-task interventions. However, the specific timing of in-process intervention mattered little; groups showed no significant changes in readiness once discussion was underway.

These results have several important theoretical implications for research on formal interventions, group development, and group decision making. First, this research elaborates on theory on formal interventions by examining when interventions are given and illustrating the different effects of in-process and pre-task interventions. Many prior studies have found smallerthan-expected effects of pre-task interventions and thus have concluded that their effects are too small to overcome pre-discussion preferences and the biases they introduce (Larson et al., 1994; Greitemeyer et al., 2006). The studies presented here suggest a different interpretation, namely that interventions are less effective when given pre-task; thus, scholars may have underestimated the potential effects of some formal interventions. Interventions should be most effective when they trigger recursive dynamics that compound with time (Walton, 2014). With in-process interventions, groups can observe changes that result from interventions by comparing the process before and after intervention. This comparison should allow groups to perceive the intervention's value, motivating them to continue to try to apply its advice and creating a virtuous, self-sustaining cycle. 


\section{IN-PROCESS INTERVENTIONS}

Although the particular intervention and process changes studied here are specific to group decision making, advantages of in-process interventions should be manifest in any task in which groups give up too early. For example, in-process interventions for group brainstorming should have similar effects because brainstorming groups tend to prematurely move from generating ideas to selecting them (Rietzschel, Nijstad, \& Stroebe, 2006). Formal interventions, such as instructions to defer judgment (Sutton \& Hargadon, 1996), should be more effective in process than pre-task. Future research should compare in-process interventions and pre-task interventions in a variety of tasks, focusing on tasks in which persistence is a problem.

Second, these studies also suggest that scholars of group development should view the moment interaction begins as one of significant change in group state. In prior research, the "beginning" of group work has meant a variety of things, including the first activity a group performs (Woolley, 1998), the first meeting (Gersick, 1988), and the first half of a task (Gersick, 1989; Lim \& Murnighan, 1994). These times have been theorized as important primarily because they establish interaction patterns and trajectories for much of the group's task (Ericksen \& Dyer, 2004). This research suggests a more specific aspect of group beginnings: the qualitative change that occurs from prospective to real interaction. Building on construal level theory, these studies suggest a specific moment when groups change in their readiness to focus on and change their own processes. Because group process is temporally distant and hypothetical before interaction, members have higher-level construals of it (Trope \& Liberman, 2010), thus making questions of "how" seem less valuable. During interaction, group process is temporally proximate and concrete, making it more likely that groups will focus on their own processes. Such explanations may also shed light on why groups increase their task focus over time (e.g., 


\section{IN-PROCESS INTERVENTIONS}

Bales \& Strodbeck, 1951; Chang et al., 2001) or why discussing task strategy pre-task is so difficult for groups (Hackman et al., 1976; Woolley, 1998).

This paper also highlights several issues unique to groups that need to process distributed information. Specifically, in-process interventions can help decision-making groups by extending their discussions, which has been shown to improve the depth and thoroughness of information processing (Kelly \& Karau, 1999; Parks \& Cowlin, 1995). Although some decisions are best made quickly (e.g., Dijksterhuis, 2004), and ineffective teams may delay making decisions (Eisenhardt, 1989), groups with distributed information must carefully pool and process information to avoid falling victim to well-known pitfalls (Brodbeck et al, 2007). Inprocess interventions may lengthen discussion in two ways: by encouraging groups to follow a more thorough process and by interrupting them to create "attention switches," which may have useful spillover effects on other aspects of group processes (Okhuysen \& Eisenhardt, 2001). Further, these studies suggest that group decision processes are more malleable than some models of group development predict (e.g., Gersick \& Hackman, 1990; Hackman \& Wageman, 2005); decision-making groups do not quickly form intransigent processes that can be substantially altered only at the beginning or temporal midpoint. Instead, decision-making groups may be quite flexible throughout their interactions.

Last, these results support a non-linear view of temporal issues in decision-making groups (e.g., Arrow, Poole, Henry, Wheelan, \& Moreland, 2004) - namely, that not all minutes are created equal. The specific timing of in-process interventions mattered surprisingly little, but a difference of only a few minutes mattered a great deal if those minutes included the onset of discussion. For instance, the gap between earlier and later interventions in Study 1 (10 minutes) was twice as large as the gap between pre-task and early interventions in Study 2 (5 minutes), but 
the latter difference was more consequential. This suggests an event-based view of time in group decision making marked by critical events. Rather than emphasizing gradual change and development over time (e.g., Chang et al., 2001) or clock-based temporal pacing (e.g., Gersick, 1988), group decision-making researchers should focus more on events such as the end of information pooling or requests for consensus in understanding temporality and readiness for change in decision-making groups.

\section{Limitations and Future Research}

These studies have several limitations that suggest directions for future research. First, these tasks were all performed by ad-hoc groups in the laboratory. As with all such research, one must question the extent to which ongoing teams in different contexts would exhibit similar dynamics. Existing research suggests that familiarity likely has competing effects in intervention readiness. When members are familiar with each other, groups are more likely to pool distributed information than when all members are strangers, making familiar groups less likely to need interventions at all (Gruenfeld et al., 1996). Familiarity among team members also allows groups to be more flexible in switching their attention (Okhuysen \& Waller, 2002) but also more focused on members' relational (rather than task-related) concerns (Okhuysen, 2001). Further, familiar groups might be better able to imagine the interaction process, allowing members to construe group process at a lower level. However, ongoing groups may still often need intervention, as groups can maintain norms against processing information through as many as 30 decisions (Gigone \& Hastie, 1997). Future research should investigate the extent to which familiarity among members and team stability attenuate the advantage that in-process interventions enjoy over pre-task ones. 


\section{IN-PROCESS INTERVENTIONS}

These studies should also not be interpreted as evidence that pre-task interventions are universally ineffective. Indeed, there is ample evidence that team training, which can be seen as an elaborate pre-task intervention, is more effective when given to a team as a whole than to individual members (e.g., Salas, Burke, Bowers, \& Wilson, 2001) because such training facilitates the formation of transactive memory systems (Liang, Moreland, \& Argote, 1995; Moreland \& Myaskovsky, 2000) and shared mental models of the task (Marks, Zaccaro, \& Mathieu, 2000). However, future research will need to investigate whether team training interventions would be more effective if administered to in-process teams (see Salas, et al., 2008), extending these findings over larger timeframes.

This research also does not address the extent to which groups require process improvement. Interventions may serve only as distractions when the most obvious or ingrained responses are already appropriate (Hackman, Brousseau, \& Weiss, 1976; Gersick \& Hackman, 1990). In such instances, in-process interventions can disrupt group process more than pre-task interventions. There may also be instances in which early group actions are irrevocable and create path dependence for future actions. In these cases, waiting to intervene may be too costly. Future research should investigate task boundaries of in-process interventions and whether there are specific contexts, tasks, or types of interventions that are better given pre-task-or even not at all.

Drawing clear causal inferences from the self-report data given here (i.e., Perceived Value, Intervention Understanding, Process Accountability) may also be problematic. These selfreport measures were taken after both decisions were made; group members likely were aware of whether they pooled unshared information and, possibly, when they found a "hidden" correct answer. Thus, groups may have inferred that the intervention had been valuable because they 


\section{IN-PROCESS INTERVENTIONS}

gleaned new information from the discussion, rather than the reverse. Further, although the application of construal-level theory provides a potential explanation for intervention readiness, these construal levels were not directly measured. Future research should seek to manipulate specific indicators of intervention readiness, such as perceived value and construal level, and assess changes immediately after interaction begins rather than after discussion is complete.

\section{Conclusion}

Overall, these studies suggest that interventions in decision-making groups require a tweak of Benjamin Franklin's old adage: an ounce of cure is more valuable than an ounce of prevention. In-process interventions outperformed pre-task interventions because groups saw more value in them, leading to correspondingly larger changes in processes and outcomes. By integrating temporality and group readiness into our understanding of formal interventions, scholars and practitioners can develop better understandings of how to alter the trajectory of decision-making groups and why such changes occur. 


\section{References}

Arrow, H., Poole, M., S., Henry, K., B., Wheelan, S., \& Moreland, R. (2004). Time, change, and development: The temporal perspective on groups. Small Group Research, 35(1), 73-105.

Bales, R. F., \& Strodtbeck, F. L. (1951). Phases in group problem-solving. Journal of Abnormal and Social Psychology, 46, 485-494. doi:10.1037/h0059886

Ballinger, G. A. (2004). Using generalized estimating equations for longitudinal data analysis. Organizational Research Methods, 7, 127-150. doi:10.1177/1094428104263672

Baron, R. M. \& Kenny, D. A. (1986). The moderator/mediator variable distinction in social psychological research: Conceptual, strategic, and statistical considerations. Journal of Personality and Social Psychology, 51(6), 1173-1182.

Bettenhausen, K. L., \& Murnighan, J. K. (1985). The emergence of norms in competitive decision-making groups. Administrative Science Quarterly, 30, 350-372. doi: $10.2307 / 2392667$

Brodbeck, F. C., Kerschreiter, R., Mojzisch, A., \& Schulz-Hardt, S. (2007). Group decision making under conditions of distributed knowledge: The information asymmetries model. Academy of Management Review, 32, 459-479. doi:10.5465/AMR.2007.24351441

Chang, A., Bordia, P., \& Duck, J. (2003). Punctuated equilibrium and linear progression: Toward a new understanding of group development. Academy of Management Journal, 46, 106117. doi: $10.2307 / 30040680$

De Dreu, C. K. W., Koole, S. L., \& Steinel, W. (2000). Unfixing the fixed pie: A motivated information-processing approach to integrative negotiation. Journal of Personality and Social Psychology, 79, 975-987. doi: 10.1037//0022-35I4.79.6.975 


\section{IN-PROCESS INTERVENTIONS}

Dijksterhuis, A. (2004). Think different: The merits of unconscious thought in preference development and decision making. Journal of Personality and Social Psychology, 87(5), 586-598. http://doi.org/10.1037/0022-3514.87.5.586

Eisenhardt, K. M. (1989). Making fast strategic decisions in high-velocity environments. Academy of Management Journal, 32(3), 543-576.

Ericksen, J., \& Dyer, L. (2004). Right from the start: Exploring the effects of early team events on subsequent project team development and performance. Administrative Science Quarterly, 49(3), 438-471.

Eyal, T., Liberman, N., Trope, Y., \& Walther, E. (2004). The pros and cons of temporally near and distant action. Journal of Personality and Social Psychology, 86(6), 781.

Fisher, B. A. (1970). Decision emergence: Phases in group decision-making. Speech Monographs, 37(1), 53-66.

Gersick, C. J. G. (1988). Time and transition in work teams: Toward a new model of group development. Academy of Management Journal, 31(1), 9-41.

Gersick, C. J. G. (1989). Marking time: Predictable transitions in task groups. Academy of Management Journal, 32, 274-309. doi:10.2307/256363

Gersick, C. J. G., \& Hackman, J. R. (1990). Habitual routines in task-performing groups. Organizational Behavior and Human Decision Processes, 47, 65-97. doi:10.1016/07495978(90)90047-D

Gigone, D., \& Hastie, R. (1993). The common knowledge effect: Information sharing and group judgment. Journal of Personality and Social Psychology, 65(5), 959-974.

Gigone, D., \& Hastie, R. (1997). The impact of information on small group choice. Journal of Personality and Social Psychology, 72(1), 132-140. 


\section{IN-PROCESS INTERVENTIONS}

Greitemeyer, T., \& Schulz-Hardt, S. (2003). Preference-consistent evaluation of information in the hidden profile paradigm: Beyond group-level explanations for the dominance of shared information in group decisions. Journal of Personality and Social Psychology, 84, 322-339.

Greitemeyer, T., Schulz-Hardt, S. Brodbeck, F. C., \& Frey, D. (2006). Information sampling and group decision making: The effects of an advocacy decision procedure and task experience. Journal of Experimental Psychology: Applied, 12, 31-42. doi: 10.1037/1076-898X.12.1.31

Gruenfeld, D. H., Mannix, E. A., Williams, K. Y., \& Neale, M. A. (1996). Group composition and decision making: How member familiarity and information distribution affect process and performance. Organizational Behavior and Human Decision Processes, 67(1), 1-15.

Hackman, J. R., \& Wageman, R. (2005). A theory of team coaching. Academy of Management Review, 30, 269-287. doi:10.5465/AMR.2005.16387885

Hackman, J. R., Brousseau, K. R., \& Weiss, J. A. (1976). The interaction of task design and group performance strategies in determining group effectiveness. Organizational Behavior and Human Performance, 16(2), 350-365.

Hayes, A. F., Preacher, K. J. (2014). Statistical mediation analysis with a multicategorical independent variable. British Journal of Mathematical and Statistical Psychology, 67, 451470. doi:10.1111/bmsp.12028

Hayes, A. F. (2013). Introduction to mediation, moderation, and conditional process analysis: A regression-based approach. New York, NY: Guildford Press.

Henry, R. A. (1995). Improving group judgment accuracy: Information sharing and determining the best member. Organizational Behavior and Human Decision Processes, 62, 190-197. http://doi.org/10.1006/obhd.1995.1042 


\section{IN-PROCESS INTERVENTIONS}

Hilbe, J. M. (2011). Negative binomial regression (second edition). Cambridge, UK: Cambridge University Press.

Hochwarter, W.A., Ferris, G.R., Perrewé, P.L., Hall, A.T., \& Frink, D.D (2007). Political skill as moderator of the felt-accountability-job performance relationship. Organizational Behavior and Human Decision Processes, 102, 226-239. doi:10.1016/j.obhdp.2006.09.003

Huber, P. (1977). Robust methods of estimation of regression coefficients. Statistics: A Journal of Theoretical and Applied Statistics, 8(1), 41-53.

Janis, I. L. (1982). Groupthink. Boston: Houghton Mifflin.

Jehn, K. A., \& Mannix, E. A. (2001). The dynamic nature of conflict: A longitudinal study of intragroup conflict and group performance. Academy of Management Journal, 44(2), 238251.

Kaplan, R. E. (1979). The conspicuous absence of evidence that process consultation enhances task performance. Journal of Applied Behavioral Science, 15, 346-360. doi:10.1177/002188637901500309

Kelly J. R., \& Karau, S. J. (1999). Group decision making: The effects of initial preferences and time pressure. Personality and Social Psychology Bulletin, 25, 1342-1354. doi: $10.1177 / 0146167299259002$

Kozlowski, S. W. J., \& Bell, B. S. (2008). Team learning, development, and adaptation. In V. I. Sessa \& M. London (Eds.), Group learning (pp. 15-44). Mahwah, NJ: LEA.

Kruglanski, A. W., \& Webster, D. M. (1996). Motivated closing of the mind: "Seizing” and “freezing.” Psychological Review, 103(2), 263. 


\section{IN-PROCESS INTERVENTIONS}

Kruglanski, A. W., Webster, D. M., \& Klem, A. (1993). Motivated resistance and openness to persuasion in the presence or absence of prior information. Journal of Personality and Social Psychology, 65(5), 861.

Larson, J. R., Jr., Foster-Fishman, P. G., \& Keys, C. B. (1994). Discussion of shared and unshared information in decision-making groups. Journal of Personality and Social Psychology, 67(3), 446-461.

Lerner, J. S., \& Tetlock, P. E. (1999). Accounting for the effects of accountability. Psychological Bulletin, 125(2), 255-275.

Liang, D. W., Moreland, R., \& Argote, L. (1995). Group Versus Individual Training and Group Performance: The Mediating Role of Transactive Memory. Personality and Social Psychology Bulletin, 21(4), 384-393. https://doi.org/10.1177/0146167295214009

Lim, S. G., \& Murnighan, J. K. (1994). Phases, deadlines, and the bargaining process. Organizational Behavior and Human Decision Processes, 58, 153-171. doi:10.1006/obhd.1994.1032

Loyd, D. L., Wang, C. S., Phillips, K. W., \& Lount. R. B. (2013). Social category diversity promotes premeeting elaboration: The role of relationship focus. Organization Science, 24, 757-772. doi: 10.1287/orsc.1120.0761

Lu, L., Yuan, Y. C., \& McLeod, P. L. (2012). Twenty-five years of hidden profiles in group decision-making: A meta-analysis. Personality and Social Psychology Review, 16, 54-75. doi: $10.1177 / 1088868311417243$

Marks, M. A., Mathieu, J. E., \& Zaccaro, S. J. (2001). A temporally based framework and taxonomy of team processes. Academy of Management Review, 26(3), 356-376. 


\section{IN-PROCESS INTERVENTIONS}

Mennecke, B. E. (1997). Using group support systems to discover hidden profiles: an examination of the influence of group size and meeting structures on information sharing and decision quality. International Journal of Human-Computer Studies, 47, 387-405. doi: $1071-5819 / 97 / 090387$

Mesmer-Magnus, J. R., \& DeChurch, L. A. (2009). Information sharing and team performance: A meta-analysis. Journal of Applied Psychology, 94, 535-546. doi: 10.1037/a0013773

Moreland, R. L., \& Myaskovsky, L. (2000). Exploring the Performance Benefits of Group Training: Transactive Memory or Improved Communication? Organizational Behavior and Human Decision Processes, 82(1), 117-133. https://doi.org/10.1006/obhd.2000.2891

Okhuysen, G. A. (2001). Structuring change: Familiarity and formal interventions in problemsolving groups. Academy of Management Journal, 44, 794-808. doi:10.2307/3069416

Okhuysen, G. A., \& Eisenhardt, K. M. (2002). Integrating knowledge in groups: How formal interventions enable flexibility. Organization Science, 13, 370-386. doi:10.1287/orsc.13.4.370.2947

Okhuysen, G. A., \& Waller, M. J. (2002). Focusing on midpoint transitions: An analysis of boundary conditions. Academy of Management Journal, 45, 1056-1065. doi: $10.2307 / 3069330$

Parkinson, C. N. (1955). Work Expands To Fill The Time Available For Its Completion, The Economist, 1955(November). Retrieved http://www.economist.com/node/14116121.

Parks, C. D., \& Cowlin, R. (1995). Group discussion as affected by number of alternatives and by a time limit. Organizational Behavior and Human Decision Processes, 62, 267-275. doi:10.1006/obhd.1995.1049 


\section{IN-PROCESS INTERVENTIONS}

Preacher, K. J. \& Hayes, A. F. (2008). Asymptotic and resampling strategies for assessing and comparing indirect effects in multiple mediator models. Behavior Research Methods, 40, 879-891. doi: 10.3758/BRM.40.3.879

Preacher, K. J. \& Leonardelli, G. J. (2015). Calculation for the Sobel test: An interactive calculation tool for mediation tests [Online calculator and instructions]. Retrieved from http://www.quantpsy.org/sobel/

Rietzschel, E. F., Nijstad, B. A., \& Stroebe, W. (2006). Productivity is not enough: A comparison of interactive and nominal brainstorming groups on idea generation and selection. Journal of Experimental Social Psychology, 42, 244-251.

http://doi.org/10.1016/j.jesp.2005.04.005

Salas, E., Burke, C. S., Bowers, C. A., \& Wilson, K. A. (2001). Team training in the skies: Does crew resource management (CRM) training work? Human Factors, 43(4), 641-674.

Salas, E., DiazGranados, D., Klein, C., Burke, C. S., Stagl, K. C., Goodwin, G. F., \& Halpin, S. M. (2008). Does Team Training Improve Team Performance? A Meta-Analysis. Human Factors: The Journal of the Human Factors and Ergonomics Society, 50(6), 903-933. https://doi.org/10.1518/001872008X375009

Scholten, L., van Knippenberg, D., Nijstad, B. A., \& De Dreu, C. K. W. (2007). Motivated information processing and group decision-making: Effects of process accountability on information processing and decision quality. Journal of Experimental Social Psychology, 43, 539-552. doi:10.1016/j.jesp.2006.05.010

Sobel, M. E. (1982). Asymptotic intervals for indirect effects in structural equations models. In S. Leinhart (Ed.), Sociological methodology (pp. 290-312). San Francisco: Jossey-Bass. 
Stasser, G., \& Birchmeier, Z. (2003). Group creativity and collective choice. In P. B. Paulus \& B. A. Nijstad (Eds.), Group creativity: Innovation through collaboration (pp. 85-109). Oxford, UK: Oxford University Press.

Stasser, G., \& Titus, W. (1985). Pooling of unshared information in group decision making: Biased information sampling during discussion. Journal of Personality and Social Psychology, 48, 1467-1478. doi:10.1037/0022-3514.48.6.1467

Stasser, G., Taylor, L. A., \& Hanna, C. (1989). Information sampling in structured and unstructured discussions of three- and six-person groups. Journal of Personality and Social Psychology, 57(1), 67-78.

Sutton, R. I., \& Hargadon, A. (1996). Brainstorming groups in context: Effectiveness in a product design firm. Administrative Science Quarterly, 41(4), 685-718.

Tindale, R. S., \& Sheffey, S. (2002). Shared information, cognitive load, and group memory. Group Processes \& Intergroup Relations, 5(1), 5-18.

Trope, Y., \& Liberman, N. (2010). Construal-level theory of psychological distance. Psychological Review, 117(2), 440.

Tuckman, B. W. (1965). Developmental sequence in small groups. Psychological Bulletin, 63, 384-399. doi:10.1037/h0022100

van Ginkel, W. P., \& van Knippenberg, D. (2008). Group information elaboration and group decision making: The role of shared task representations. Organizational Behavior and Human Decision Processes, 105(1), 82-97. https://doi.org/10.1016/j.obhdp.2007.08.005

Van Swol, L. M., \& Ludutsky, C. L. (2007). Tell me something I don't know: Decision makers' preference for advisors with unshared information. Communication Research, 34, 297-312. doi:10.1177/0093650207300430 


\section{IN-PROCESS INTERVENTIONS}

Van Swol, L. M., Savadori, L., \& Sniezek, J. A. (2003). Factors that may affect the difficulty of uncovering hidden profiles. Group Processes and Intergroup Relations, 6, 285-304.

Wageman, R., Fisher, C. M., \& Hackman, J. R. (2009). Timing is everything: The importance of finding the right moment in leading teams. Organizational Dynamics, 38, 192-203. doi: 10.1016/j.orgdyn.2009.04.004

Winquist, J. R., \& Larson, J. R. (1998). Information pooling: When it impacts group decision making. Journal of Personality and Social Psychology, 74(2), 371-377.

Wittenbaum, G. M., Hollingshead, A. B., \& Botero, I. C. (2004). From cooperative to motivated information sharing in groups: Moving beyond the hidden profile paradigm. Communication Monographs, 71, 286-310. doi:10.1080/0363452042000299894

Woodward, B. (2004). Plan of attack. New York: Simon and Schuster.

Woolley, A. W. (1998). Effects of intervention content and timing on group task performance. Journal of Applied Behavioral Science, 34, 30-46. doi:10.1177/0021886398341002

Zellmer-Bruhn, M., Waller, M. J., \& Ancona, D. (2004). The effect of temporal entrainment on the ability of teams to change their routines. In S. Blount (Ed.), Time in groups: Research on managing groups and teams (Volume 6) (pp. 135-158). Bingley, UK: Emerald Group Publishing Limited. 
Table 1

GEEs Testing the Effects of In-process Interventions and In-process Intervention Timing on Group Processes and Decisions in Study 1

\begin{tabular}{|c|c|c|c|c|c|c|}
\hline Dependent Variables & $\begin{array}{c}\text { Model } 1 \\
\text { Discussion Time }\end{array}$ & $\begin{array}{c}\text { Model } 2 \\
\text { Preference } \\
\text { Negotiation }\end{array}$ & $\begin{array}{c}\text { Model } 3 \\
\text { Information } \\
\text { Pooling }^{\mathrm{a}}\end{array}$ & $\begin{array}{c}\text { Model } 4 \\
\text { Information } \\
\text { Pooling }^{\mathrm{a}}\end{array}$ & $\begin{array}{c}\text { Model } 5 \\
\text { Decision Quality }^{\mathrm{b}}\end{array}$ & $\begin{array}{c}\text { Model } 6 \\
\text { Decision Quality }\end{array}$ \\
\hline Predictors & $B(S E)$ & $B(S E)$ & $B(S E)$ & $B(S E)$ & $B(S E)$ & $B(S E)$ \\
\hline Intercept & $14.24 * * *(.87)$ & $-.10(.10)$ & $2.73 * * *(.04)$ & $2.34 * * *(.07)$ & $-.03(.32)$ & $-5.01 * *(1.57)$ \\
\hline Task 1 Dummy & $4.71 * * *(.75)$ & $.33 * * *(.08)$ & $-.03(.03)$ & $-.09 *(.03)$ & $.07(.33)$ & $-.09(.49)$ \\
\hline Initial Preferences & $.54(.75)$ & $-.10(.08)$ & $.03(.02)$ & $.02(.02)$ & $1.62 * * *(.40)$ & $1.81 * * *(.53)$ \\
\hline In-process Contrast (H1) & $7.26^{* * *}(1.41)$ & $-.73 * * *(.20)$ & $.28 * * *(.06)$ & $.02(.05)$ & $1.37 * *(.47)$ & $-.29(.67)$ \\
\hline Midpoint Contrast (H3) & $2.80^{+}(1.67)$ & $.05(.22)$ & $.03(.04)$ & $-.01(.04)$ & $.18(.64)$ & $.03(.65)$ \\
\hline Discussion Length & & & & $.03 * * *(.00)$ & & $.07(.05)$ \\
\hline Preference Negotiation & & & & $-.20 * * *(.02)$ & & $-.90 *(.39)$ \\
\hline Unshared Info. Pooling & & & & & & $.25^{*}(.12)$ \\
\hline \multicolumn{7}{|l|}{ Goodness of Fit Indices } \\
\hline QIC & 4962.24 & 104.30 & 9.22 & 5.48 & 142.25 & 111.43 \\
\hline QICC & 4960.67 & 103.01 & 18.63 & 18.92 & 141.77 & 111.25 \\
\hline
\end{tabular}

${ }^{a}$ Negative binomial link function specified

${ }^{\mathrm{b}}$ Logistic link function specified; Coded $0=$ incorrect, $1=$ correct

${ }^{+} p<.10 ; * p<.05, * * p<.01, * * * p<.001\left(\right.$ Wald $\left.\chi^{2}\right)$ 


\section{IN-PROCESS INTERVENTIONS}

Table 2

Estimated Marginal Means by Condition in Study 1

\begin{tabular}{|c|c|c|c|c|c|c|c|c|c|c|c|c|}
\hline Condition & & ussion $\mathrm{T}$ & & Prefer & ce Negoti & on $(Z)$ & Unsha & nformat & ooled & & ision Qua & \\
\hline & Task 1 & Task 2 & Total & Task 1 & Task 2 & Total & Task 1 & Task 2 & Total & Task 1 & Task 2 & Total \\
\hline Pre-task $(\mathrm{n}=27)$ & 14.40 & 9.69 & 12.05 & $.66(.19)$ & $.33(.19)$ & $.49(.18)$ & 13.99 & 14.49 & 14.23 & $.50(.11)$ & $.49(.12)$ & $.49(.11)$ \\
\hline & $(1.27)$ & $(1.24)$ & $(1.20)$ & & & & (.90) & (.96) & $(.90)$ & & & \\
\hline In-process $(n=37)$ & 21.63 & 16.92 & 19.27 & $-.07(.12)$ & $-.40(.14)$ & $-.23(.12)$ & 19.52 & 20.24 & 19.88 & $.80(.06)$ & $.79(.07)$ & $.79(.06)$ \\
\hline & $(.98)$ & $(.97)$ & $(.90)$ & & & & $(.71)$ & $(.62)$ & $(.58)$ & & & \\
\hline $\operatorname{Early}(\mathrm{n}=19)$ & 20.26 & 15.55 & 17.91 & $-.09(.17)$ & $-.42(.19)$ & $-.26(.18)$ & 19.05 & 19.74 & 19.39 & $.78(.08)$ & $.77(.09)$ & $.78(.08)$ \\
\hline Midpoint $(\mathrm{n}=18)$ & $\begin{array}{l}23.07 \\
(1.25)\end{array}$ & $\begin{array}{l}18.35 \\
(1.30)\end{array}$ & $\begin{array}{l}20.71 \\
(1.21)\end{array}$ & $-.04(.15)$ & $-.37(.16)$ & $-.21(.15)$ & $\begin{array}{c}(.89) \\
20.04 \\
(.92)\end{array}$ & $\begin{array}{c}(.88) \\
20.76 \\
(.80)\end{array}$ & $\begin{array}{c}(.83) \\
20.40 \\
(.80)\end{array}$ & $.81(.08)$ & $.80(.09)$ & $.81(.08)$ \\
\hline
\end{tabular}

Note: Cells display Estimated Marginal Means $(S E)$, controlling for initial Preferences $=.55$. 
Table 3

Tests of Indirect Effects and Mediation in Study 1

\begin{tabular}{|c|c|c|c|c|c|c|}
\hline & \multicolumn{3}{|c|}{ Bootstrapping Approach } & \multicolumn{2}{|c|}{ Sobel Test via GEEs ${ }^{\mathrm{a}}$} & \multirow[t]{2}{*}{ Causal Steps Approach } \\
\hline & \multicolumn{3}{|c|}{ 99\% C.I. } & & & \\
\hline & Effect (SE) & $L L$ & $U L$ & Sobel Z (SE) & $p$ & \\
\hline 1. In-process $\rightarrow$ Info $\rightarrow$ DQ & $1.16(.45)$ & .39 & 2.56 & $3.22(.04)$ & .001 & Full \\
\hline 2. In-process $\rightarrow$ Length $\rightarrow$ Info & $2.45(.60)$ & 1.16 & 4.26 & $4.20(.04)$ & $<.001$ & Partial \\
\hline 3. In-process $\rightarrow$ Pref $\rightarrow$ Info & $2.20(.50)$ & 1.06 & 3.81 & $2.99(.03)$ & .003 & Partial \\
\hline 4. Length $\rightarrow$ Info $\rightarrow$ DQ & $.11(.03)$ & .04 & .21 & $3.04(.02)$ & .002 & Full \\
\hline 5. In-process $\rightarrow$ Length $\rightarrow$ Info $\rightarrow$ DQ & $.60(.26)$ & .15 & 1.47 & $\mathrm{n} / \mathrm{a}$ & $\mathrm{n} / \mathrm{a}$ & $\mathrm{n} / \mathrm{a}$ \\
\hline 6. Pref $\rightarrow$ Info $\rightarrow$ DQ & $-.76(.27)$ & -1.55 & -.19 & $-3.32(.02)$ & $<.001$ & Marginally Full \\
\hline 7. In-process $\rightarrow$ Pref $\rightarrow$ Info $\rightarrow$ DQ & $.45(.23)$ & .06 & 1.21 & $\mathrm{n} / \mathrm{a}$ & $\mathrm{n} / \mathrm{a}$ & $\mathrm{n} / \mathrm{a}$ \\
\hline
\end{tabular}

Note: All tests reported here control for initial preferences and Task. Chains beginning with "In-process" also control for the Midpoint Contrast Code, following Hayes and Preacher's (2014) recommendation to control for other categorical variables, such that $k-1$ categories are represented in the analysis.

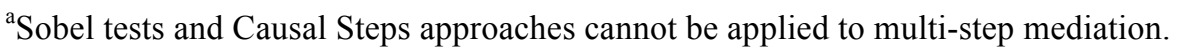

Legend: In-process $=$ In-process Contrast Code; Length $=$ Discussion Length; Pref $=$ Preference Negotiation; Info = Unshared Information Pooling; DQ = Decision Quality 
Table 4

GEEs Testing the Effects of In-process Interventions and In-process Intervention Timing on Group Processes and Decisions in Study 2

\begin{tabular}{|c|c|c|c|c|c|c|}
\hline & $\begin{array}{c}\text { Model } 1 \\
\text { Discussion Time }\end{array}$ & $\begin{array}{c}\text { Model } 2 \\
\text { Preference } \\
\text { Negotiation }\end{array}$ & $\begin{array}{c}\text { Model } 3 \\
\text { Information } \\
\text { Pooling }^{\mathrm{a}} \\
\end{array}$ & $\begin{array}{c}\text { Model } 4 \\
\text { Information } \\
\text { Pooling }^{\mathrm{a}} \\
\end{array}$ & $\begin{array}{c}\text { Model } 5 \\
\text { Decision Quality }^{\mathrm{b}}\end{array}$ & $\begin{array}{c}\text { Model } 6 \\
\text { Decision Quality }\end{array}$ \\
\hline Predictors & $B(S E)$ & $B(S E)$ & $B(S E)$ & $B(S E)$ & $B(S E)$ & $B(S E)$ \\
\hline Intercept & $12.92 * * *(.74)$ & $.03(.13)$ & $2.64 * * *(.05)$ & $2.17 * * *(.10)$ & $-1.41 * * *(.39)$ & $-4.28 * * *(1.05)$ \\
\hline Task 1 Dummy & $1.77 * *(.63)$ & $.01(.08)$ & $-.03(.04)$ & $-.08 *(.04)$ & $-.11(.41)$ & $.18(.50)$ \\
\hline Initial Preferences & $-.09(.55)$ & $-.05(.08)$ & $.00(.03)$ & $.01(.03)$ & $2.00 * * *(.36)$ & $2.28 * * *(.42)$ \\
\hline In-process Contrast (H1) & $3.09 *(1.25)$ & $-.62(.25)^{*}$ & $.18 *(.08)$ & $-.04(.06)$ & $.51(.54)$ & $.21(.55)$ \\
\hline Immediate Contrast (H4) & $.95(1.56)$ & $-.09(.28)$ & $.08(.09)$ & $.06(.07)$ & $.53(.59)$ & $.64(.59)$ \\
\hline Discussion Length & & & & $.03 * * *(.01)$ & & $-.12^{+}(.07)$ \\
\hline Preference Negotiation & & & & $-.18 * * *(.02)$ & & $.04(.27)$ \\
\hline Unshared Info. Pooling & & & & & & $.29 * *(.09)$ \\
\hline \multicolumn{7}{|l|}{ Goodness of Fit Indices } \\
\hline QIC & 3388.55 & 120.72 & 17.86 & 11.33 & 139.61 & 125.16 \\
\hline QICC & 3386.87 & 118.75 & 26.67 & 24.30 & 138.27 & 125.85 \\
\hline
\end{tabular}

${ }^{\mathrm{a} N e g a t i v e ~ b i n o m i a l ~ l i n k ~ f u n c t i o n ~ s p e c i f i e d ~}$

${ }^{\mathrm{b}}$ Logistic link function specified; Coded $0=$ incorrect, $1=$ correct

${ }^{+} p<.10, * p<.05, * * p<.01, * * * p<.001$ (Wald $\chi^{2}$ ) 


\section{IN-PROCESS INTERVENTIONS}

Table 5

Estimated Marginal Means by Condition in Study 2

\begin{tabular}{|c|c|c|c|c|c|c|c|c|c|c|c|c|}
\hline Condition & & ussion T & & Pref & ence Nego & ation & & red Info & & & ision Qua & \\
\hline & Task 1 & Task 2 & Total & Task 1 & Task 2 & Total & Task 1 & Task 2 & Total & Task 1 & Task 2 & Total \\
\hline Pre-task $(\mathrm{n}=20)$ & $\begin{array}{l}12.57 \\
(1.03)\end{array}$ & $\begin{array}{c}10.80 \\
(1.04)\end{array}$ & $\begin{array}{c}11.69 \\
(.99)\end{array}$ & $.41(.22)$ & $.42(.23)$ & $.42(.22)$ & $\begin{array}{c}12.21 \\
(.86)\end{array}$ & $\begin{array}{c}12.60 \\
(.97)\end{array}$ & $\begin{array}{c}12.40 \\
(.88)\end{array}$ & $.32(.11)$ & $.35(.11)$ & $.34(.10)$ \\
\hline In-process $(\mathrm{n}=40)$ & $\begin{array}{l}15.66 \\
(.79)\end{array}$ & $\begin{array}{l}13.90 \\
(.89)\end{array}$ & $\begin{array}{l}14.78 \\
(.78)\end{array}$ & $-.21(.14)$ & $-.20(.16)$ & $-.21(.15)$ & $\begin{array}{l}14.59 \\
(.70)\end{array}$ & $\begin{array}{l}15.05 \\
(.77)\end{array}$ & $\begin{array}{l}14.82 \\
(.68)\end{array}$ & $.45(.09)$ & $.47(.10)$ & $.46(.08)$ \\
\hline Immediate $(\mathrm{n}=20)$ & $\begin{array}{l}15.19 \\
(1.19)\end{array}$ & $\begin{array}{l}13.42 \\
(1.27)\end{array}$ & $\begin{array}{l}14.30 \\
(1.19)\end{array}$ & $-.17(.22)$ & $-.16(.23)$ & $-.16(.22)$ & $\begin{array}{l}14.00 \\
(1.09)\end{array}$ & $\begin{array}{l}14.45 \\
(1.18)\end{array}$ & $\begin{array}{c}14.22 \\
(1.10)\end{array}$ & $.38(.12)$ & $.41(.12)$ & $.40(.11)$ \\
\hline $\operatorname{Early}(\mathrm{n}=20)$ & $\begin{array}{l}16.14 \\
(1.03)\end{array}$ & $\begin{array}{l}14.37 \\
(1.11)\end{array}$ & $\begin{array}{l}15.28 \\
(1.03)\end{array}$ & $-.26(.17)$ & $-.25(.19)$ & $-.25(.17)$ & $\begin{array}{l}15.18 \\
(.79)\end{array}$ & $\begin{array}{l}15.67 \\
(.85)\end{array}$ & $\begin{array}{l}15.42 \\
(.77)\end{array}$ & $.51(.11)$ & $.54(.12)$ & $.52(.10)$ \\
\hline
\end{tabular}

Note: Cells display Estimated Marginal Means $(S E)$, controlling for initial Preferences $=.57$. 
Table 6

Tests of Indirect Effects and Mediation in Study 2

1. In-process $\rightarrow$ Info $\rightarrow$ DQ

2. In-process $\rightarrow$ Length $\rightarrow$ Info

3. Length $\rightarrow$ Info $\rightarrow$ DQ

4. In-process $\rightarrow$ Length $\rightarrow$ Info $\rightarrow$ DQ

5. In-process $\rightarrow$ Pref $\rightarrow$ Info

6. Pref $\rightarrow$ Info $\rightarrow$ DQ

7. In-process $\rightarrow$ Pref $\rightarrow>$ Info $\rightarrow$ DQ

8. In-process $\rightarrow$ Value $\rightarrow$ Length

9. Value $\rightarrow$ Length $\rightarrow$ Info

10. In-process $\rightarrow>$ Value $\rightarrow$ Length $\rightarrow$ Info

11. Value $\rightarrow$ Length $\rightarrow$ Info $\rightarrow$ DQ

12. In-process $\rightarrow>$ Value $\rightarrow$ Length $\rightarrow$ Info $\rightarrow$ DQ

Bootstrapping Approach

Sobel Test via GEEs ${ }^{\mathrm{a}}$

Causal Steps Approach ${ }^{\mathrm{a}}$

99\% C.I.

\begin{tabular}{cccccc}
\hline Effect $(S E)$ & $L L$ & $U L$ & Sobel $Z(S E)$ & $p$ & \\
\hline $.52(.27)$ & .01 & 1.46 & $1.97(.02)$ & .05 & No Step 1 \\
$1.31(.43)$ & .30 & 2.63 & $2.19(.04)$ & .03 & Full
\end{tabular}

$.13(.05)$

$.37(.20)$

.04

.28

$3.12(.00)$

.002

No Step 1

.95 (.38)

.05

1.07

$\mathrm{n} / \mathrm{a}$

$\mathrm{n} / \mathrm{a}$

$\mathrm{n} / \mathrm{a}$

$-.39(.17)$

.17

2.15

$2.22(.05)$

.03

Full

$-.93$

$-.07$

$-2.68(.01)$

.01

Full

$.83(.34)$

.03

.79

$\mathrm{n} / \mathrm{a}$

$\mathrm{n} / \mathrm{a}$

$\mathrm{n} / \mathrm{a}$

$.89(.27)$

.12

1.93

$1.78(.47)$

.07

Full

$.32(.14)$

.34

1.73

$2.60(.02)$

$<.001$

Partial

$.24(.12)$

.07

.85

$\mathrm{n} / \mathrm{a}$

$\mathrm{n} / \mathrm{a}$

$\mathrm{n} / \mathrm{a}$

.09 (.05)

.06

.68

$\mathrm{n} / \mathrm{a}$

$\mathrm{n} / \mathrm{a}$

$\mathrm{n} / \mathrm{a}$

Note: All tests reported here control for initial preferences and Task. Chains beginning with "In-process" also control for the Immediate Contrast Code, following Hayes and Preacher's (2014) recommendation to control for other categorical variables, such that $k-1$ categories are represented in the analysis.

${ }^{a}$ Sobel tests and Causal Steps approaches cannot be applied to multi-step mediation.

Legend: In-process $=$ In-process Contrast Code; Value $=$ Perceived Value; Length $=$ Discussion Length; Pref $=$ Preference Negotiation; Info $=$ Unshared Information Pooling; DQ = Decision Quality 


\section{IN-PROCESS INTERVENTIONS}

Table 7

GEEs Exploring Potential Correlates of Intervention Readiness on Discussion Time, Information Sharing, and Decision Quality in Study 2

Model $1 \quad$ Model $2 \quad$ Model $2 \quad$ Model 3

Discussion Time Preference Negotiation $\quad$ Information Pooling $^{\mathrm{a}} \quad$ Decision Quality $^{\mathrm{b}}$

\begin{tabular}{lcccc}
\hline Predictors & $B(S E)$ & $B(S E)$ & $B(S E)$ & $B(S E)$ \\
Intercept & $15.97^{+}(8.56)$ & $3.28^{* *}(1.25)$ & $1.91^{* *}(.60)$ & $-7.58^{+}(4.59)$ \\
Task 1 Dummy & $1.76^{* *}(.64)$ & $-.01(.08)$ & $-.03(.04)$ & $-.10(.42)$ \\
Initial Preferences & $-.03(.56)$ & $-.05(.08)$ & $.01(.03)$ & $2.05^{* * *}(.38)$ \\
In-process Contrast & $2.29^{+}(1.30)$ & $-.56(.27)$ & $.11(.09)$ & $.40(.62)$ \\
Immediate Contrast & $.44(1.38)$ & $.02(.26)$ & $.03(.08)$ & $.37(.60)$ \\
Int. Understanding (H2a) & $-1.01(.95)$ & $-.13(.16)$ & $-.04(.07)$ & $.38(.36)$ \\
Perceived Value (H2b) & $2.29^{* *}(.79)$ & $-.13(.13)$ & $.16^{* *}(.06)$ & $.10(.30)$ \\
Proc. Accountability (H2c) & $-1.63(1.22)$ & $-.39^{+}(.24)$ & $.03(.09)$ & $.74(.64)$ \\
\hline Goodness of Fit Indices & & & & 143.24 \\
QIC & 3051.36 & 122.45 & 17.45 & 140.33 \\
QICC & 3045.79 & 117.75 & 31.04 & \\
\hline
\end{tabular}

${ }^{\mathrm{a}}$ Negative binomial link function specified

${ }^{b}$ Logistic link function specified; Coded $0=$ incorrect, $1=$ correct

${ }^{+} p<.10 ; * p<.05, * * p<.01, * * * p<.001$ (Wald $\chi^{2}$ ) 


\section{Appendix A}

Table A1

Distribution of Shared and Unshared Information for Hidden Profile Tasks

\begin{tabular}{|c|c|c|c|c|}
\hline & \multicolumn{2}{|c|}{$\begin{array}{c}\text { Incorrect Choices } \\
\text { (i.e., Chef } \mathrm{A} / \mathrm{C} ; \text { Location } \mathrm{X} / \mathrm{Y} \text { ) }\end{array}$} & \multicolumn{2}{|c|}{$\begin{array}{l}\text { Correct Choices } \\
\text { (i.e., Chef B; Location Z) }\end{array}$} \\
\hline & Shared & Unshared & Shared & Unshared \\
\hline \multirow[t]{2}{*}{ Member 1} & 5 positive & 1 neutral & 2 neutral & 3 positive \\
\hline & 1 neutral & 2 negative & 4 negative & \\
\hline \multirow[t]{2}{*}{ Member 2} & 5 positive & 1 neutral & 2 neutral & 3 positive \\
\hline & 1 neutral & 2 negative & 4 negative & \\
\hline \multirow[t]{2}{*}{ Member 3} & 5 positive & 1 neutral & 2 neutral & 3 positive \\
\hline & 1 neutral & 2 negative & 4 negative & \\
\hline \multirow[t]{2}{*}{ Manifest Profile } & 5 positive & 3 neutral & 2 neutral & 9 positive \\
\hline & 1 neutral & 6 negative & 4 negative & \\
\hline
\end{tabular}

When a separate sample of 13 three-person groups was given manifest profiles before discussion, $100 \%$ of their decisions were in favor of the intended correct decisions. 


\section{IN-PROCESS INTERVENTIONS}

\section{Appendix B}

Table B1

GEEs Testing Timing of Process Changes by Condition in Study 1

\begin{tabular}{lccc} 
& $\begin{array}{c}\text { Model 1 } \\
\text { Discussion } \\
\text { Ongoing }^{\mathrm{b}}\end{array}$ & $\begin{array}{c}\text { Model 2 } \\
\text { Preference Negotiation }\end{array}$ & $\begin{array}{c}\text { Model 3 } \\
\text { Information Pooling }^{\mathrm{a}}\end{array}$ \\
\hline Predictors (df) & $\chi^{2}$ & $\chi^{2}$ & $\chi^{2}$ \\
Intercept (1) & $533.11^{* * *}$ & $22.08^{* * *}$ & $29.90^{* * *}$ \\
Period (10) & $1327.32^{* * *}$ & $198.01^{* * *}$ & $241.22^{* * *}$ \\
Initial Preferences (1) & $\mathrm{c}$ & $4.94^{*}$ & 2.01 \\
Condition (2) & $53.29^{* * *}$ & $14.92^{* * *}$ & $23.52^{* * *}$ \\
Condition*Period (20) & $8532.39^{* * *}$ & $152.28^{* * *}$ & $58.53^{* * *}$ \\
\hline Goodness of Fit Indices & & & \\
QIC & 553.39 & 374.61 & 510.17 \\
QICC & 575.39 & 392.27 & 531.94 \\
\hline
\end{tabular}

$* p<.05, * * * p<.001$

Notes: Model 1, 3: $n=768$ observations (i.e., 12 periods per group); Model 2: $n=425$ (periods after decisions had been made were excluded)

${ }^{a}$ Negative binomial link function specified

${ }^{b}$ Logistic link function specified. This binary variable describes whether a group has ended discussion $(0)$ or is continuing an ongoing discussion (1).

${ }^{\mathrm{c}}$ Variable was excluded because Hessian Matrix is singular when included, making estimates incalculable

Table B2

GEEs Testing Timing of Process Changes by Condition in Study 2

\begin{tabular}{lccc} 
& Model 1 & Model 2 & Model 3 \\
& $\begin{array}{c}\text { Discussion } \\
\text { Ongoing }\end{array}$ & $\begin{array}{c}\text { Preference Negotiation } \\
\text { Information Pooling }\end{array}$ \\
\hline Predictors (df) & $\chi^{2}$ & $\chi^{2}$ & $\chi^{2}$ \\
Intercept (1) & $1463.41^{* * *}$ & $3.63^{+}$ & $3077.86^{* * *}$ \\
Period (7) & $436.34^{* * *}$ & $88.41^{* * *}$ & $400.13^{* * *}$ \\
Initial Preferences (1) & $\mathrm{c}$ & 8.78 & .20 \\
Condition (2) & $50.54^{* * *}$ & $8.13^{*}$ & 1.05 \\
Condition*Period (14) & 10.10 & $33.36^{* *}$ & $34.74^{* *}$ \\
\hline Goodness of Fit Indices & & & \\
QIC & 372.32 & 327.70 & 78.44 \\
QICC & 388.32 & 333.42 & 122.12 \\
\hline
\end{tabular}

${ }^{+} p<.10 ; * p<.05, * * p<.01, * * * p<.001$

Notes: Model 1, 3: $\mathrm{n}=480$ observations (i.e., 8 periods per group); Model 2: $\mathrm{n}=351$ (periods after decisions had been made were excluded)

${ }^{a}$ Negative binomial link function specified.

${ }^{b}$ Logistic link function specified; This binary variable describes whether a group has ended discussion $(0)$ or is continuing an ongoing discussion (1).

${ }^{c}$ Variable was excluded because Hessian Matrix is singular when included, making estimates incalculable. 